faster $(\leq 220 \mathrm{~min})$ compared with slower $(>220 \mathrm{~min})$ time from LKW to revascularization were not associated with statistically significant differences in outcome. There were no statistically differences in safety outcomes in faster compared to slower times.

Conclusions Among patients with acute ischemic stroke due to large vessel occlusion, faster time from arterial puncture to revascularization is strongly associated with improved angiographic and 3 month clinical outcomes. These data emphasize the importance of rapid and efficient catheter navigation, device deployment, and clot retrieval for best patient outcomes.

Disclosures A. Jadhav: None. R. Gupta: None. E. Levy: None. O. Zaidat: None. D. Yavagal: None. J. Saver: None.

\section{P-022 ENDOVASCULAR TREATMENT OF WIDE-NECK BIFURCATION ANEURYSMS: A SINGLE-CENTER EXPERIENCE AND PARADIGM SHIFT}

A Copelan*, J Delgado Almandoz, Y Kayan, J Scholz. Neurointerventional Radiology, Abbott Northwestern Hospital, Minneapolis, MN

\subsection{6/neurintsurg-2021-SNIS.58}

Purpose To present our single center experience utilizing balloon-assisted coiling (BAC), stent-assisted coiling (SAC) and Woven Endo-Bridge (WEB) embolization for the treatment of both ruptured and unruptured wide-necked bifurcation aneurysms (WNBAs) with a focus on the safety and efficacy profiles of each technique.

Methods We retrospectively reviewed all WNBAs treated at our institution with BAC, SAC, and WEB embolization between January 2012 and August 2020. Required aneurysm characteristics were in line with the pivotal WEB Intrasaccular Therapy (WEB-IT) study and included: ruptured or unruptured status; size of dome between $3 \mathrm{~mm}$ and $10 \mathrm{~mm}$; wide-neck defined by neck size $\geq 4 \mathrm{~mm}$ or dome-to-neck ratio $<2$; and location limited to the basilar tip (BTA), internal carotid artery terminus (ICA-T), anterior communicating artery complex (ACOM), and middle cerebral artery (MCA) bifurcation. We collected patient demographic variables, aneurysm characteristics, intraprocedural technical difficulties (ITDs), perioperative complications, and aneurysm occlusion rates. Group differences were assessed and logistic regression models were utilized to analyze more complex relationships.

Results Three hundred one aneurysms met inclusion criteria and included 141 in the BAC group, 81 in the SAC group, and 79 in the WEB group. Nearly $27 \%$ of aneurysms were ruptured and the mean maximum aneurysm size was $6.3 \mathrm{~mm}$ $( \pm 1.9 \mathrm{~mm})$, mean neck $3.4 \mathrm{~mm}( \pm 1.3 \mathrm{~mm})$, and dome-to-neck ratio $1.6( \pm 0.5)$. There was a $6 \%$ incidence of ITDs in the WEB cohort, significantly less than the $17 \%$ incidence in SAC $(p=0.03)$, and resulting new persistent neurological deficits occurred in 5\% of SACs and 4\% of BACs, higher than the WEB cohort in which there were none, and this approached statistical significance $(p=0.09)$. Adequate aneurysm occlusion rates were achieved at significantly higher rates with SAC (90\%) and WEB embolization (85\%) compared to BAC (75\%) $(\mathrm{p}=0.014)$.

Conclusion The WEB device is a valuable addition to the neurointerventionalist's armamentarium, permitting adequate occlusion of challenging WNBAs often not suitable for BAC and with an improved safety profile relative to SAC.

Abstract P-022 Table 1 Procedure time, procedural related complications and clinical outcomes

\begin{tabular}{|c|c|c|c|c|c|}
\hline & $\begin{array}{l}\text { BAC } \\
(n=141)\end{array}$ & $\begin{array}{l}\text { SAC } \\
(n=81)\end{array}$ & $\begin{array}{l}\text { WEB } \\
(\mathrm{n}=79)\end{array}$ & TOTAL & P-values \\
\hline Procedure time (mins) & $\begin{array}{l}51.1 \pm \\
25.7\end{array}$ & $\begin{array}{l}86.6 \pm \\
38.5\end{array}$ & $\begin{array}{l}46.5 \pm \\
25.3\end{array}$ & $\begin{array}{l}61.6 \pm \\
35.4\end{array}$ & $\begin{array}{l}0.282 \\
<0.001\end{array}$ \\
\hline $\begin{array}{l}\text { Intraprocedural technical } \\
\text { difficulties: }\end{array}$ & $10(7.1 \%)$ & $\begin{array}{l}14 \\
(17.2 \%)\end{array}$ & $5(6.3 \%)$ & $\begin{array}{l}25 \\
(8.3 \%)\end{array}$ & $\begin{array}{l}0.823 \\
0.032\end{array}$ \\
\hline Thromboembolic event & $4(2.8 \%)$ & $8(9.9 \%)$ & $5(6.3 \%)$ & $\begin{array}{l}17 \\
(5.6 \%)\end{array}$ & $<0.001$ \\
\hline $\begin{array}{l}\text { Intraprocedural aneurysm rupture } \\
\text { or vessel perforation }\end{array}$ & $4(2.8 \%)$ & $2(2.5 \%)$ & $0(0 \%)$ & $\begin{array}{l}6 \\
(2.0 \%)\end{array}$ & \\
\hline Device migration & $2(1.4 \%)$ & $1(1.2 \%)$ & $0(0 \%)$ & $\begin{array}{l}3 \\
(0.9 \%)\end{array}$ & \\
\hline $\begin{array}{l}\text { Coil stretching/premature } \\
\text { detachment }\end{array}$ & $0(0 \%)$ & $3(3.7 \%)$ & $0(0 \%)$ & $\begin{array}{l}3 \\
(0.9 \%)\end{array}$ & \\
\hline $\begin{array}{l}\text { Clinically significant deficit } \\
\text { resulting from intraprocedural } \\
\text { technical difficulty }\end{array}$ & $6(4.3 \%)$ & $4(4.9 \%)$ & $0(0 \%)$ & $\begin{array}{l}10 \\
(3.3 \%)\end{array}$ & $\begin{array}{l}0.090 \\
0.120\end{array}$ \\
\hline $\begin{array}{l}\text { Post-procedure neurological } \\
\text { complication }\end{array}$ & $5(3.5 \%)$ & $8(9.9 \%)$ & $3(3.8 \%)$ & $\begin{array}{l}16 \\
(5.3 \%)\end{array}$ & $1,0.21$ \\
\hline Perioperative infarction & $4(2.8 \%)$ & $6(7.4 \%)$ & $3(3.8 \%)$ & $\begin{array}{l}13 \\
(4.3 \%)\end{array}$ & 0.723 \\
\hline Intracerebral hemorrhage & $1(0.7 \%)$ & $2(2.5 \%)$ & $0(0 \%)$ & $\begin{array}{l}3 \\
(0.9 \%)\end{array}$ & \\
\hline $\begin{array}{l}\text { Clinically significant deficit } \\
\text { resulting from post-procedure } \\
\text { complication }\end{array}$ & $2(1.4 \%)$ & $4(4.9 \%)$ & $1(1.3 \%)$ & $\begin{array}{l}7 \\
(2.3 \%)\end{array}$ & $1,0.367$ \\
\hline $\begin{array}{l}\text { Major disabling neurological } \\
\text { complications }\end{array}$ & $8(5.7 \%)$ & $5(6.2 \%)$ & $1(1.3 \%)$ & $\begin{array}{l}14 \\
(4.7 \%)\end{array}$ & $\begin{array}{l}0.162 \\
0.210\end{array}$ \\
\hline Procedure related death & $1(0.7 \%)$ & $2(2.5 \%)$ & $0(0 \%)$ & $\begin{array}{l}3 \\
(1.0 \%)\end{array}$ & $1,0.497$ \\
\hline
\end{tabular}

*When a single $p$-value is provided, this corresponds to a global value for BAC vs. SAC vs. WEB † When two $p$-values are provided, the first value corresponds to WEB vs. BAC and the second value corresponds to WEB vs. SAC

Abstract P-022 Table 2 Angiographic occlusion and retreatment

\begin{tabular}{llllll}
\hline & $\begin{array}{l}\text { BAC } \\
(\mathbf{n}=120)\end{array}$ & $\begin{array}{l}\text { SAC } \\
(\mathbf{n}=73)\end{array}$ & $\begin{array}{l}\text { WEB } \\
(\mathbf{n}=71)\end{array}$ & TOTAL & P-values \\
\hline Complete occlusion & $47(39.2 \%)$ & $64(87.7 \%)$ & $40(56.3 \%)$ & $\begin{array}{l}151 \\
(57.2 \%)\end{array}$ & $<0.001$ \\
& & & & $65(24.6 \%)$ & $<0.001$ \\
Neck remnant & $43(35.8 \%)$ & $2(2.7 \%)$ & $20(28.2 \%)$ & 0.014 \\
Adequate Occlusion & $90(75.0 \%)$ & $66(90.4 \%)$ & $60(84.5 \%)$ & 216 & 0.014 \\
Aneurysm remnant & $30(25.0 \%)$ & $7(9.6 \%)$ & $11(15.5 \%)$ & $48(18.2 \%)$ & 0.014 \\
Aneurysm & $21(17.5 \%)$ & $4(5.5 \%)$ & $6(8.5 \%)$ & $31(11.7 \%)$ & 0.014 \\
Retreatment & & & & & \\
\hline
\end{tabular}

†For complete occlusion and neck remnant, the p-values provided correspond to a global value for $B A C$ vs. SAC vs. WEBțFor adequate occlusion, aneurysm remnant, and aneurysm retreatment, the $p$-values correspond to WEB + SAC vs. BAC 
Disclosures A. Copelan: None. J. Delgado Almandoz: 2; C; Microvention/Terumo. Y. Kayan: 2; C; Microvention/Terumo. J. Scholz: None.

\section{P-023 SPOKE-ADMINISTERED INTRAVENOUS ALTEPLASE AND OUTCOMES FOR LARGE VESSEL OCCLUSION STROKE PATIENTS IN A HUB-AND-SPOKE TELESTROKE MODEL}

\begin{abstract}
${ }^{1} \mathrm{R}$ Regenhardt*, ${ }^{2} \mathrm{~J}$ Rosenthal, ${ }^{2} \mathrm{~A}$ Awad, ${ }^{2} \mathrm{~N}$ Nolan, ${ }^{2} \mathrm{~J}$ Mclntyre, ${ }^{2} \mathrm{C}$ Whitney, ${ }^{1} \mathrm{~N}$ Alotaibi, ${ }^{3} \mathrm{~J}$ Vranic, ${ }^{1} \mathrm{C}$ Stapleton, ${ }^{1} \mathrm{~A}$ Patel, ${ }^{2} \mathrm{~N}$ Rost, ${ }^{2} \mathrm{~L}$ Schwamm, ${ }^{1} \mathrm{~T}$ Leslie-Mazwi. ${ }^{1}$ Neurosurgery, Massachusetts General Hospital, Boston, MA; ${ }^{2}$ Neurology, Massachusetts General Hospital, Boston, MA; ${ }^{3}$ Neuroradiology, Massachusetts General Hospital, Boston, MA
\end{abstract}

\subsection{6/neurintsurg-2021-SNIS.59}

Introduction The role of intravenous alteplase treatment for emergent large vessel occlusion (ELVO) stroke patients who ultimately undergo endovascular thrombectomy (EVT) has been questioned in recent randomized trials. However, most patients enrolled in these trials presented directly to an EVTcapable hub center (i.e. 'mothership' model). We aimed to compare outcomes for ELVO patients transferred to our hub for EVT consideration who were administered alteplase at spoke hospitals (i.e. 'drip and ship' model) versus those who were not.

Methods ELVO stroke patients who presented to 25 spoke hospitals from January 1, 2018 to June 30, 2020 were retrospectively identified from a prospectively maintained database. Inclusion criteria were transfer for EVT consideration, spoke hospital CTA-defined ELVO, and spoke hospital Alberta stroke program early CT score (ASPECTS) $\geq 6$. ELVO was defined as occlusion of the internal carotid artery terminus, first or second segment of the middle cerebral artery, or basilar artery. Outcomes of interest included adequate reperfusion (TICI 2b3 ), any intracerebral hemorrhage (ICH), hub discharge functional independence (modified Rankin scale, mRS $\leq 2$ ), and 90-day $\mathrm{mRS} \leq 2$.

Results Inclusion criteria were met for 258 patients. Their median age was 70 years (IQR 60-81), median NIHS stroke scale (NIHSS) was 13 (6-19), and 50\% were female. 38\% were treated with alteplase at spoke hospitals, and there were no significant differences in baseline characteristics comparing those treated and those not treated except for last known well-to-Telestroke consult time (median 1.6 vs 6.7 hours, $\mathrm{p}<0.0001$ ). 44\% ultimately underwent EVT at the hub with $87 \%$ achieving TICI 2b-3. Spoke-administered alteplase was not associated with ICH $(\mathrm{OR}=1.042,95 \% \mathrm{CI}=0.390,2.784$, $\mathrm{p}=0.935)$ and trended toward association with greater TICI 2b-3 $(\mathrm{OR}=3.589, \quad 95 \% \mathrm{CI}=0.940,13.70, \quad \mathrm{p}=0.062)$. Spokeadministered alteplase independently increased the odds of discharge $\mathrm{mRS} \leq 2(\mathrm{aOR}=2.568,95 \% \mathrm{CI}=1.159,5.686, \mathrm{p}=0.020)$ and 90-day $\mathrm{mRS} \leq 2 \quad(\mathrm{aOR}=3.307, \quad 95 \% \mathrm{CI}=1.591,6.874$, $\mathrm{p}=0.001$ ), even when controlling for last known well, NIHSS, and EVT in multivariable models.

Conclusion In this cohort of 258 patients who first presented to spoke hospitals as potential EVT candidates with CTA-defined ELVO and ASPECTS $\geq 6$, treatment with intravenous alteplase at spoke hospitals before transfer significantly increased the odds of discharge and 90-day functional independence without increasing the odds of ICH. Intravenous alteplase should not be withheld from ELVO patients who first present to spoke hospitals capable of its administration but requiring transfer for EVT. Additional studies are warranted to confirm benefits of spoke- administered alteplase in other hub-and-spoke models and to understand the minimum distance and transfer time associated with benefit.

Disclosures R. Regenhardt: None. J. Rosenthal: None. A. Awad: None. N. Nolan: None. J. McIntyre: None. C. Whitney: None. N. Alotaibi: None. J. Vranic: None. C. Stapleton: None. A. Patel: None. N. Rost: None. L. Schwamm: None. T. Leslie-Mazwi: None.

\section{P-024 NATIONAL TRENDS IN ENDOVASCULAR AND SURGICAL TREATMENT OF IDIOPATHIC INTRACRANIAL HYPERTENSION}

${ }^{1} \mathrm{H}$ Saber*, ${ }^{1} \mathrm{R}$ Jahan, ${ }^{1} \mathrm{~S}$ Tateshima, ${ }^{2} \mathrm{G}$ Colby, ${ }^{1} \mathrm{~N}$ Kaneko, ${ }^{1} \mathrm{M}$ Nour, ${ }^{1} \mathrm{~V}$ Szeder, ${ }^{1} \mathrm{~K}$ Khatibi, ${ }^{1} \mathrm{~L}$ Ponce Mejia, ${ }^{3} \mathrm{D}$ Liebeskind, ${ }^{1} \mathrm{G}$ Duckwiler. I'Interventional Neuroradiology, UCLA, Los Angeles, CA; ${ }^{2}$ Neurosurgery, UCLA, Los Angeles, CA; ${ }^{3}$ Neurology, UCLA, Los Angeles, CA

\subsection{6/neurintsurg-2021-SNIS.60}

Introduction/Purpose Patterns in utilization and characteristics of endovascular venous stenting (EVS) for Idiopathic Intracranial Hypertension (IIH) are unknown. We aimed to explore the frequency and characteristics of EVS for IIH in the United States, and to compare with admissions undergoing Optic nerve sheath fenestration (ONF) or Shunting.

Materials and Methods In this retrospective longitudinal crosssectional analysis, hospitalizations with a diagnosis of IIH were identified in the National Inpatient Sample (2010-2017), excluding venous thrombosis and other causes of intracranial hypertension. Temporal trends in utilization of EVS, ONF, and shunt procedures were explored. Logistic regression was used to measure differences according to age, race, sex, and other patient and hospital-level characteristics.

Results Between 2010 and 2017, 784 EVS, 352 ONF and 11803 shunting procedures were identified for the treatment of IIH. Among those undergoing EVS, median age was 32 (IQR 28-40), 93.1\% were women, and 73.5\% of EVS procedures were elective admissions. Total IIH-related hospitalizations increased from 11350 in 2010 to 24684 in 2017. Patient age, sex or race were not associated with EVS use, but urban-teaching hospital setting, and larger

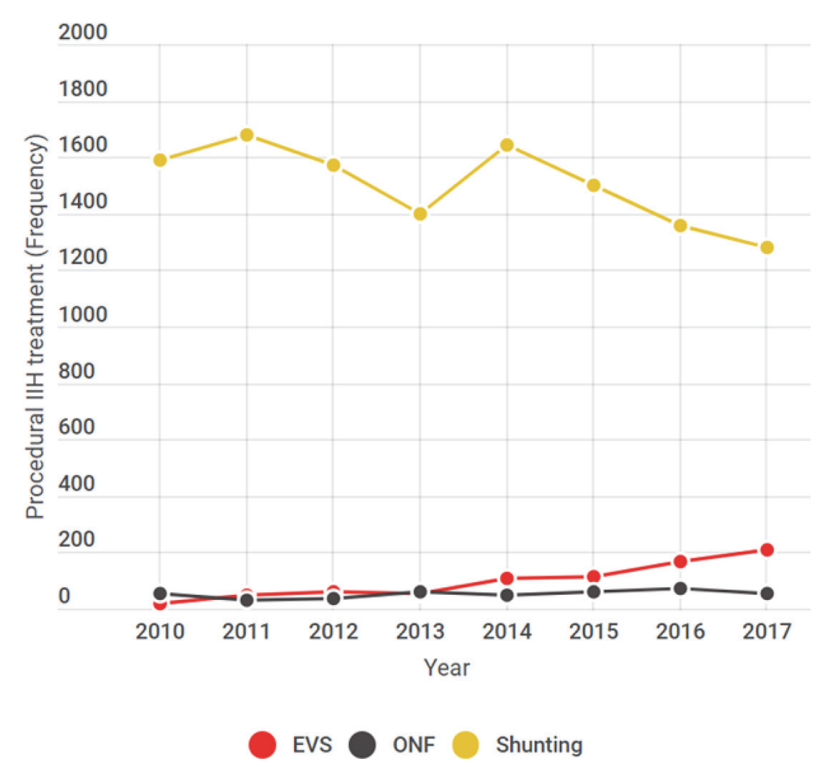

Abstract P-024 Figure 1 